\title{
PENGARUH PERENCANAAN PEMBELAJARAN TERHADAP PENINGKATAN KUALITAS MENGAJAR GURU DI SD NEGERI 060938 MEDAN JOHOR
}

\author{
Srie Faizah Lisnasari \\ Surel: sriefaizah2502@gmail.com
}

\begin{abstract}
This study aims to determine the application of Teacher learning plan in SD Negeri 060938 Medan Johor, to know the quality of teaching teachers and to know the effect of lesson planning on improving the quality of teaching Teachers at SD Negeri 060938 Medan Johor. The study population is all teachers in SD Negeri 060938 Medan Johor which amounts to 23 people. The results of this study illustrates that the professionalism of teachers SD Negeri 060938 Medan Johor in teaching is quite good and has achieved the goal of learning as expected, as the results showed that $49.60 \%$ success is supported by teachers who have quality competencies and master the material quality curriculum is also reflected in the evaluation results of the semester exam the value of its objectivity is in the category on very well..
\end{abstract}

Keywords: Learning Planning, Teaching Quality, Elementary School Teachers.

\begin{abstract}
ABSTRAK
Penelitian ini bertujuan untuk mengetahui penerapan perencanaan pembelajaran Guru di SD Negeri 060938 Medan Johor, untuk mengetahui kualitas mengajar guru dan untuk mengetahui pengaruh perencanaan pembelajaran terhadap peningkatan kualitas mengajar Guru di SD Negeri 060938 Medan Johor. Populasi penelitian adalah seluruh guru di SD Negeri 060938 Medan Johor yang berjumlah 23 orang. Hasil penelitian menggambarkan bahwa Profesionalisme guru SD Negeri 060938 Medan Johor dalam mengajar tergolong sangat baik dan telah mencapai tujuan pembelajaran sesuai harapan sebagaimana hasil penelitian menunjukkan bahwa 49,60\% keberhasilan ditunjang oleh guru yang mempunyai kompetensi yang berkualitas dan menguasai materisesuai kurikulum kualitas ini pula tercermin pada hasil evaluasi ujian semester nilai objektivitasnya berada dalam kategori pada sangat baik.
\end{abstract}

Kata Kunci: Perencanaan Pembelajaran, Kualitas Mengajar, Guru SD

\section{PENDAHULUAN}

Upaya mencerdaskan kehidupan bangsa tidaklah dapat dipungkiri bahwa penyelenggaraan pendidikan merupakan suatu hal yang mutlak dilakukan. Tolok ukur suatu kemajuan bangsa amatlah ditentukan oleh kecerdasan yang dimiliki oleh bangsa tersebut. Mengingat pentingnya ilmu pengetahuan dan pelaksanaan amanah untuk mencerdaskan kehidupan bangsa yang tercantum dalam pasal 31 ayat 1 UUD 1945 telah ditegaskan mengenai azas pemerataan memperoleh pendidikan sebagai berikut. "Tiap-tiap warga berhak mendapatkan pengajaran". Mendapatkan pengajaran itu merupakan hak, namun hal ini dapat berarti wajib bagi setiap warga negara untuk turut serta dalam upaya 
Srie Faizah Lisnasari: Pengaruh Perencanaan...

menciptakan warga negara yang cerdas. Dari tujuan pendidikan nasional yang dirumuskan pada pasal 3: Pendidikan Nasioanl berfungsi mengembangkan kemampuan dan membentuk watak serta peradaban bangsa yang yang bermartabat dalam rangka mencerdaskan kehidupan bangsa, bertujuan untuk berkembangnya potensi peserta didik agar menjadi manusia yang sehat, berilmu, cakap, mandiri, dan menjadi warga negara yang demokratis serta bertanggung jawab.

Perencanaan pembelajaran sangat penting terhadap pencapaian target dimaksudkan disini adalah penyelesaian keseluruhan bahan atau materi pembelajaran yang telah ditetapkan kurikulum tersebut. Manakala perencanaan pembelajaran tersebut tidak disusun atau direncanakan dengan matang, maka kemudian target yang ingin dicapai dalam kurikulum tersebut tidak tercapai pula. Perencanaan bukanlah hal yang gampang, berbagai factor yang harus diperhatikan agar pembelajaran itu dapat berlangsung secara efesien dan efektif. Sebagai suatu sistem, pembelajaran terdiri dari komponen yang saling terkait. Antara satu komponen dengan komponen lainnya harus berjalan secara serasi untuk mencapai tujuan pembelajaran yang sudah ditetapkan. Disinilah terlihat bagaimana pentingnya merencanakan kegiatan pembelajaran agar dapat berjalan dengan baik. Guru sebagai yang melaksanakan kegiatan pembelajaran sangat berkepentingan dengan perencanaan pembelajaran. Hal ini tentu terkait dengan upaya meningkatkan kualitas pembelajaran yang akan dilaksanakan.

Di samping itu, perencanaan yang dibuat oleh guru sekaligus dapat dijadikan sebagai ukuran untuk memulai tingkat keberhasilan guru dalam melaksanakan kegiatan pembelajaran. Masalah yang dihadapi di sekolah adalah terkadang masih ada guru yang menganggap remeh perencanaan, hal ini biasanya terjadi karena guru beranggapan bahwa pembelajaran yang dilakukannya merupakan tugas rutin sehingga tidak perlu lagi direncanakan. Untuk melihat seberapa jauh guru melakukan kegiatan perencanaan pembelajaran dan bagaimana pengaruhnya terhadap kualitas pembelajaran, khususnya di SD Negeri 060938 Medan Johor.

\section{METODE PENELITIAN}

Adapun teknik yang digunakan dalam mengumpulkan data riset lapangan adalah sebagai berikut: Observasi, Questioner atau angket, dan Dokumentasi. Jenis penelitian ini adalah penelitian deskriptif kuantitatif atau penelitian sensus dimana penulis mengambil seluruh populasi dalam penelitian ini. Lokasi penelitian di SD Negeri 060938 Medan Johor. Populasi adalah jumlah keseluruhan subyek penelitian. Adapun jumla populasi dalam penelitian ini adalah seluruh guru SD Negeri 060938 Medan Johor, sebanyak 23 orang. Sampel 
adalah sebagian dari jumlah karakteristik yang dimiliki oleh populasi tersebut. Maka penulis mengambil seluruh populasi dalam penelitian ini, sehingga dikatakan penelitian populasi (sampel Jenuh).

Eksistensi instrument dalam suatu penelitian menjadi salah satu unsur penting karena berfungsi sebagai alat bantu atau sarana dalam menggumpulkan data yang dapat dipertanggungjawabkan

kebenarannya. Penulis menggunakan instrument penelitian yaitu:

a. Panduan Observasi, adalah alat pengumpulan data yang digunakan dalam mengamati dan mencatat secara sistematis gejalagejala yang diselidiki.

b. Format dukumentasi, adalah untuk mencatat data yang bersifat dokumen.

c. Angket, adalah daftar pertanyaan yang berisi rangkaian pertanyaan tentang hal-hal yang berkaitan dengan perencanaan pengajaran terhadap peningkatan kualitas mengajar guru.

Dalam pengolahan data yang ada, penulis menggunakan metode analisis kuantitatif deskriptif yang bertujuan untuk menggambarkan atau menguraikan secara tepat tentang Perencanaan Pembelajaran Terhadap Peningkatan Kualitas Mengajar Guru Di SD Negeri 060938 Medan Johor. Analisis deskriptif kuantitatif dilakukan terhadap data, baik berupa data deskriptif kualitatif maupun data kuantitatif. Terhadap data deskriptif kuantitatif dalam hal ini data yang berupa informasi, uraian dalam bentuk bahasa, kemudian dikaitkan dengan data lainnya, sehingga memperoleh gambaran yang sudah ada. Data yang diperoleh dari angket atau ceklish, dijumlahkan ataudikelompokkan dengan menggunakan presentase yang juga disebut sebagai tabel distribusi frekuensi relatif sebab frekuensi yang disajikan dsini, bukanlahfrekuensi yang dituangkan dalam bentuk persenan.

a. Rumus yang digunakan:

$$
\mathrm{P}=\frac{\mathrm{F}}{\mathrm{N}} \times 100 \%
$$

Keterangan:

$\mathrm{F}=$ Frekuensi yang sedang dicari persentasenya

$\mathrm{P}=$ Angka persentase

$\mathrm{N}=$ Jumlah frekuensi.

b. Rumus statistika Regresi Linier sederhana

$\mathrm{Y}=a+b \mathrm{X}$

Keterangan:

$\mathrm{Y}=$ Variabel tidak bebas

$\mathrm{X}=$ Variabel bebas

$a=$ Nilai konstan

$b=$ Koefiesin arah regresi7

untuk mendapatkan nilai $a$ dan $b$ ditempuh dengan rumus:

$$
\begin{aligned}
& \mathrm{a}=\frac{(\Sigma y 1)(\Sigma x 1)-(\Sigma x 2)(\Sigma 1 y 1}{n \Sigma x 1^{2}-(x 1)^{2}} \\
& \mathrm{~b}=\frac{n(\Sigma x 1 y 1)}{n \Sigma x 1^{2}-(x 1)^{2}}
\end{aligned}
$$




\section{HASIL PENELITIAN DAN PEMBAHASAN}

Pelaksanaan

perencanaan

pembelajaran guru di SD Negeri 060938 Medan Johor pada umumnya terlaksana dengan baik, hal ini dapat kita lihat dari hasil penelitian yang menunjukkan bahwa 44,7 \% guru dalam melakukan proses pembelajaran telah menyusun rencana bahan ajar yang ditunjang oleh acuan atau bahan ajar berupa buku dan media pembelajaran. Hal ini sebagai upaya membantu siswa untuk belajar dan lebih mudah memahami apa yang dijelaskan.

Profesionalisme guru SD Negeri 060938 Medan Johor dalam mengajar tergolong sangat baik dan telah mencapai tujuan pembelajaran sesuai harapan sebagaimana hasil penelitian menunjukkan bahwa $48,6 \%$ capaian keberhasilan ditunjang oleh guru yang mempunyai kompetensi yang berkualitas dan menguasai materi sesuai kurikulum kualitas ini pula tercermin pada hasil 86 evaluasi ujian semester nilai objektivitasnya berada dalam kategori pada sangat baik.

Perencanaan pembelajaran mempunyai pengaruh yang signifikan terhadap kualitas mengajar guru di SD Negeri 060938 Medan Johor hal ini tercermin pada siswa atau murid yang berkualitas dan mempunyai tingkat pemahaman sangat baik dan hanya $6 \%$ orang guru yang memberi remedial.
Ha : Diterima

Ada pengaruh yang signifikan.

Jadi hasil yang didapat adalah, adanya Pengaruh Antara Perencanan Pembelajaran Terhadap Peningkatan Kualitas Mengajar Guru Di SD Negeri 060938 Medan Johor.

\section{Pembahasan}

SD Negeri 060938 Medan Johor berada di wilayah jl. Luku II. Tepatnya, di kelurahan Kwala Bekala, Kecamatan Medan Johor. Guru yang mengajar di SD Negeri 060938 Medan Johor terdiri dari 23 guru. Sarana yang dimiliki sekolah ini cukup lengkap, yaitu adanya ruang kamar mandi guru, ruang kamar mandi siswa, ruang kelas 1-6, ruang kantor guru, ruang kepala sekolah, mushola, dan UKS.

Fasilitas sekolah

Sebuah institusi sangat bergantung oleh sarana dan prasarana yang memadai. Baik dari segi kuantitas maupun dari segi kualitasnya yang tinggal dipelihara dalam lingkungan SD 060938 Medan Johor telah melengkapi beberapa fasilitas-fasisiltas yang menunjang kegiatan belajar-mengajar. Untuk lebih mengetahui jumlah dan jenis fasilitas yang di miliki SD 060938 Medan Johor, dapat di lihat pada tabel 1 berikut ini: 
Tabel 1. Ruangan Kelas

\begin{tabular}{|c|c|c|c|c|c|}
\hline \multirow[t]{2}{*}{$\mathrm{NO}$} & \multirow[t]{2}{*}{ JENIS RUANGAN } & \multirow[t]{2}{*}{ JUMLAH } & \multicolumn{3}{|c|}{ KONDISI RUANGAN } \\
\hline & & & $\mathrm{B}$ & $\mathrm{CB}$ & KB \\
\hline 1. & Ruang Kelas I & 1 & $\sqrt{ }$ & & \\
\hline 2. & Ruang Kelas Ii & 1 & $\sqrt{ }$ & & \\
\hline 3. & Ruang Kelas V-A dan III-A & 1 & $\sqrt{ }$ & & \\
\hline 4. & Ruang Kelas V-B dan III-B & 1 & $\sqrt{ }$ & & \\
\hline 5 . & Ruang Kelas VI-A dan IV-A & 1 & $\sqrt{ }$ & & \\
\hline 6. & Ruang Kelas VI-B dan IV-B & 1 & $\sqrt{ }$ & & \\
\hline 7 & Mushola & 1 & & $\sqrt{ }$ & \\
\hline 8. & Ruang Kamar Mandi Guru & 1 & $\sqrt{ }$ & & \\
\hline 9. & Ruang Kamar Mandi Siswa & 1 & & & $\sqrt{ }$ \\
\hline 10 . & Ruang Kepala Sekolah & 1 & $\sqrt{ }$ & & \\
\hline 11. & Ruang Uks & 1 & & $\sqrt{ }$ & \\
\hline
\end{tabular}

Keadaan Guru

SD Negeri 060938 Medan Johor diasuh oleh tenaga edukatif dengan latar belakang pendidikan Sarjana (S1). Seluruhnya baik guru tetap maupun tidak tetap. Guru-guru yang mengajar di sekolah ini hampir seluruhnya berasal dari Depertemen Pendidikan Nasional (DIKNAS), namun ada juga beberapa guru, berasal dari Depertemen Agama (DEPAG).

\section{Tentang}

penerapan

perencanaan pembelajaran di SD Negeri 060938 Medan Johor dapat dikemukakan keadaan seperti tabel 2 berikut ini:
Tabel 2. Guru memiliki penerapan pembelajaran

\begin{tabular}{c|c|c}
\hline $\begin{array}{c}\text { Alternatif } \\
\text { Jawaban }\end{array}$ & Frekuensi & Persentase \\
\hline a. sangat & 18 & 78 \\
baik & 3 & 13 \\
b. baik & 2 & 8 \\
$\begin{array}{c}\text { c. kurang } \\
\text { baik }\end{array}$ & - & - \\
$\begin{array}{c}\text { d. tidak } \\
\text { baik }\end{array}$ & & \\
\hline Jumlah & 23 & 100 \\
\hline
\end{tabular}

Berdasarkan tabel 2 di atas maka dapat dipahami bahwa $78 \%$ guru dalam mengajar proses pembelajarannya berjalan dengan sangat baik sesuai dengan harapan sebelumnya.

Berdasarkan 
keterangan di atas maka dapat ditarik kesimpulan bahwa 78\% guru yang ada di SD Negeri 060938 Medan Johor dalam proses pembelajarannya berjalan dengan sangat baik.

Tabel 3. Guru memiliki persiapan mengajar

\begin{tabular}{|c|c|c|}
\hline $\begin{array}{l}\text { Alternatif } \\
\text { Jawaban }\end{array}$ & Frekuensi & Persentase \\
\hline a. sangat & 20 & 86 \\
\hline baik & 3 & 14 \\
\hline b. baik & - & - \\
\hline $\begin{array}{l}\text { c. kurang } \\
\text { baik }\end{array}$ & - & - \\
\hline $\begin{array}{ll}\text { d. } & \text { tidak } \\
\text { baik }\end{array}$ & & \\
\hline Jumlah & 23 & 100 \\
\hline
\end{tabular}

Berdasarkan tabel di atas maka dapat dipahami bahwa $86 \%$ atau 20 orangguru dari 23 orang guru memiliki persiapan mengajar yang sangat baik. Sedangkan $14 \%$ atau 3 orang guru memiliki persiapan mengajar yang baik.

$$
\text { Di dalam proses }
$$
pembelajaran, yang harus dicapai guru ialah bagaimana tujuan pembelajaran itu akan tercapai dengan baik karena apabila guru dalam mengajartujuan tidak tercapai maka dapat di katakana guru tersebut tidak professional dalam mengajar. Hal ini dapat di jelaskan melalui tabel 4 berikut ini:

\section{Tabel 4. Tujuan pembelajaran pada setiap pertemuan tercapai sesuai dengan harapan}

\begin{tabular}{|c|c|c|}
\hline $\begin{array}{l}\text { Alternatif } \\
\text { Jawaban }\end{array}$ & Frekuensi & Persentase \\
\hline a. Sangat & 17 & 73 \\
\hline Baik & 6 & 27 \\
\hline b. Baik & - & \\
\hline $\begin{array}{ll}\text { c. } & \text { kurang } \\
& \text { baik } \\
\text { d. } & \text { tidak } \\
& \text { baik }\end{array}$ & - & \\
\hline Jumlah & 23 & 100 \\
\hline
\end{tabular}

Berdasarkan tabel di atas maka dapat dipahami bahwa $73 \%$ atau 17 orangdari 23 orang guru tujuan pembelajaran yang dibawakan tercapai dengan sangat baik, sedangkan $27 \%$ atau $6 \%$ tercapai dengan baik. Dari keterangan di atas dapat ditarik kesimpulan bahwa di SD Negeri 060938 Medan Johor 73\% atau 17 orang guru mencapai tujuan pembelajaran pada setiap pertemuan tercapai sesuai dengan harapan. Hal ini akan di bahas melalui tabel 5 di bawah ini:

Tabel 5. Guru memiliki penguasaan materi pembelajaran

\begin{tabular}{c|c|c}
\hline $\begin{array}{c}\text { Alternatif } \\
\text { Jawaban }\end{array}$ & Frekuensi & Persentase \\
\hline $\begin{array}{c}\text { a. Sangat } \\
\text { baik }\end{array}$ & 18 & 78 \\
$\begin{array}{c}\text { b. baik } \\
\text { c. kurang } \\
\text { baik }\end{array}$ & - & 22 \\
$\begin{array}{c}\text { d. tidak baik } \\
\text { Jumlah }\end{array}$ & $\mathbf{2 3}$ & $\mathbf{1 0 0}$ \\
\hline
\end{tabular}


Berdasarkan tabel 5 di atas maka dapat dipahami bahwa $78 \%$ atau 18 orangguru dari 23 orang guru yang memiliki penguasaan materi yang sangat baik. Makadari data di atas dapat di tarik kesimpulan bahwa guru yang ada di SD Negeri 060938 Medan Johor memiliki penguasaan materi yang sangat baik.

\section{Pembahasan}

Sebelum melakukan proses mengajar maka terlebih dahulu seorang guru membuat sebuah perencanaa pembelajaran. Perencanaan pembelajaran yang dimaksud ialah suatu rancangan yang disusun sebagai bahan acuan oleh guru sebelummelaksanakan pembelajaran agar dapat mencapai tujuan pembelajaran yang telah ditentukan sehingga terciptalah guru yang berkualitas dan berkompeten. Demikian halnya ketika proses mengajar berlangsung, maka seorang guru yang akan menyampaikan pelajaran kepada siswanya harus memiliki sebuah kemampuan.

Guru yang berkualitas akan menghasilkan Output yang berkualitas pula. Oleh sebab itu seorang guru harus selalu berusaha untuk meningkatkan kualitas mengajarnya dan berusaha lebih baik demi keberhasilannya mencapai tujuan pendidikan. Peningkatan kualitas mengajar guru ialah tingkat baik buruknya guru mengajar di sekolah yang sesuai dengan syarat kinerja. Dalam menyampaikan pengetahuan pada siswa atau murid didik untuk menjadikan siswa yang berkualitas.

\section{SIMPULAN}

Berdasarkan hasil penelitian serta interpretasi terhadap skripsi ini, makapenulis dapat memberikan kesimpulan sebagai berikut:

a. Pelaksanaan atau penerapan perencanaan pembelajaran guru di SD Negeri 060938 Medan Johor pada umumnya terlaksana dengan baik, hal ini dapat kita lihat dari hasil penelitian yang menunjukkan bahwa $78 \%$ guru dalam melakukan proses pembelajaran telah menyusun rencana bahan ajar yang ditunjang oleh acuan atau bahan ajar berupa buku dan media pembelajaran.hal ini sebagai upaya membantu siswa untuk belajar dan lebih mudah memahami apa yang dijelaskan.

b. Kualitas Mengajar dapat dapat dilihat dari data:

a. Persiapan mengajar: 20 orang guru memiliki persiapan mengajar sangat baik sebesar 86\%, sedangkan 3 orang atau $14 \%$ berkategori baik.

b. Kemampuan guru dalam merumuskan tujuan pembelajaran pada setiap pertemuan tercapai sesuai dengan harapan sebanyak 17 orang atau sebesar $73 \%$ sedangkan 6 orang atau 6 orang atau sebesar $27 \%$.

c. Penguasaan materi pembelajaran sangat baik dicapai oleh 18 orang guru atau sebesar $78 \%$, sedangkan 
Srie Faizah Lisnasari: Pengaruh Perencanaan...

5 orang guru atau sebesar $22 \%$ hanya mencapai kriteria baik.

d. Perencanaan Pembelajaran mempunyai pengaruh yang signifikan terhadap kualitas mengajar guru di SD Negeri 060938 Medan Johor.

DAFTAR RUJUKAN

Gulo, W. 2005. Strategi Belajar Mengajar. Jakarta : Grasindo.

Hamalik, Omar. 2005. Perencanaan Pengajaran Berdasarkan Pendekatan Sistem. Bandung: Bumi Aksara.

Hamzah B. Uno. 2008. Perencanaan Pembelajaran. Jakarta: Bumi Aksara.

Permendiknas RI No. 52 Tahun 2008 tentang Standar Proses.

Popham, W. James dan Eva L. Baker. 2005. Teknik Mengajar Secara Sistematis (Terj. Amirul Hadi, dkk). Jakarta: Rineka Cipta.

Sukmadinata, Nana Syaodih. 2002. Pengembangan Kurikulum: Teori dan Praktek. Bandung: Remaja Rosdakarya. 